\title{
Caveats of chronic exogenous corticosterone treatments in adolescent rats and effects on anxiety-like and depressive behavior and hypothalamic-pituitary-adrenal (HPA) axis function
}

\author{
Patti Waters and Cheryl M McCormick
}

\begin{abstract}
Background: Administration of exogenous corticosterone is an effective preclinical model of depression, but its use has involved primarily adult rodents. Using two different procedures of administration drawn from the literature, we explored the possibility of exogenous corticosterone models in adolescence, a time of heightened risk for mood disorders in humans.

Methods: In experiment 1, rats were injected with $40 \mathrm{mg} / \mathrm{kg}$ corticosterone or vehicle from postnatal days 30 to 45 and compared with no injection controls on behavior in the elevated plus maze (EPM) and the forced swim test (FST). Experiment 2 consisted of three treatments administered to rats from postnatal days 30 to 45 or as adults (days 70 to 85$)$ : either corticosterone $(400 \mu \mathrm{g} / \mathrm{ml})$ administered in the drinking water along with $2.5 \%$ ethanol, $2.5 \%$ ethanol or water only. In addition to testing on EPM, blood samples after the FST were obtained to measure plasma corticosterone. Analysis of variance (ANOVA) and alpha level of $P<0.05$ were used to determine statistical significance.

Results: In experiment 1, corticosterone treatment of adolescent rats increased anxiety in the EPM and decreased immobility in the FST compared to no injection control rats. However, vehicle injected rats were similar to corticosterone injected rats, suggesting that adolescent rats may be highly vulnerable to stress of injection. In experiment 2, the intake of treated water, and thus doses delivered, differed for adolescents and adults, but there were no effects of treatment on behavior in the EPM or FST. Rats that had ingested corticosterone had reduced corticosterone release after the FST. Ethanol vehicle also affected corticosterone release compared to those ingesting water only, but differently for adolescents than for adults.
\end{abstract}

Conclusions: The results indicate that several challenges must be overcome before the exogenous corticosterone model can be used effectively in adolescents.

\section{Background}

The World Health Organization has found mood disorders such as anxiety and depression to be a major contributor to disability and loss of years of health in women and in men [1]. Stressful experiences are implicated in the pathogenesis of mood disorders, and dysregulation of the hypothalamic-pituitary-adrenal (HPA) axis is a key feature of depression in particular (reviewed

\footnotetext{
* Correspondence: cmccormick@brocku.ca
Department of Psychology and Centre for Neuroscience, Brock University, St

* Correspondence: cmccormick@brocku.ca
Department of Psychology and Centre for Neuroscience, Brock University, St Catharines, Ontario, Canada
}

in [2-6]). Clinical research indicates that adolescence is a time of increased risk for mood disorders (reviewed in $[7,8])$. Changes in the reactivity of the stress systems during times of biological transitions, such as those occurring in the nervous system and gonadal systems during adolescence, are proposed to underlie the increased vulnerability [9].

The use of animal models, though not without limitations, is recognized as an important approach to understanding mood disorders [10,11]. Animal models of depression based on environmental stress (repeated 
stress exposures administered by the experimenter) have high face and construct validity [12]. Until recently, however, the focus has been on stressors in perinatal life or in adulthood rather than in adolescence [13]. Limitations of many animal models of environmental stress include the lack of control over individual differences and variation in procedures from laboratory to laboratory, which lead to inconsistencies in the literature (reviewed in $[14,15]$ ). These limitations may be especially relevant in investigations of adolescent rats, given the sensitivity of gonadal maturation to environmental factors, the ongoing development of the HPA axis, and the relatively short time frame in which adolescent development occurs [13]. One classification system for adolescence (a transitional period with no clear 'onset' or 'offset') involves three stages, a prepubescence/early adolescence period from postnatal days 21 (when rats are typically weaned in the laboratory) to 34 , a mid-adolescence period from postnatal days 34 to 46 (time in which most rats first exhibit the physical markers of puberty, such as vaginal opening and balanopreputial separation), and a late adolescence period from postnatal days 46 to 59 [16-18].

The effects of chronic or repeated stress in humans and in animal models are mediated primarily by the prolonged elevations of glucocorticoids (cortisol in humans, corticosterone in rodents) that are the endpoint of activation of the HPA axis $[19,20]$. Thus, repeated administration of exogenous corticosterone has been proposed as an effective means of circumventing some of the limitations of animal models of chronic stress exposures (reviewed in [14]). Although there is much evidence to indicate that repeated treatment with corticosterone produces reliable changes in a variety of depressive-like behaviors (reviewed in [14]), this approach has yet to be explored in adolescence. One exception is a study of a low dose of corticosterone $(20 \mathrm{mg} / \mathrm{ml})$ administered in the drinking water for 2 months (early adolescence into adulthood), which was found to decrease depression-like behavior in male mice [21]. Thus, more studies are required to assess the use of exogenous corticosterone as an animal model using higher doses and within a timeframe limited to adolescence.

Our laboratory has used a social instability stress model in rats to investigate the consequences of exposure to stressors in mid-adolescence (daily $1 \mathrm{~h}$ isolation and change of cage partner from postnatal days 30 to 45) (reviewed in [22]). Although social instability stress in adolescence produces lasting changes in neurogenesis and decrements in performance of hippocampal-dependent tasks (for example, $[23,24]$ ), effects on anxiety-like and depressive behavior have been modest $[25,26]$, perhaps because of habituation of corticosterone release to the repeated stress procedures in male rats [27]. Thus, in the present experiments, we investigated the effects of repeated administration of exogenous corticosterone over the same timeframe as our adolescent social instability procedure on anxiety-like and depressive behavior. In experiment 1 , we used a $40 \mathrm{mg} / \mathrm{kg}$ injection of corticosterone and in experiment 2 we used a 400 $\mathrm{mg} / \mathrm{ml}$ dose administered in the drinking water; both doses and administration procedures have been used extensively with adult rats (for example, injection [28-30] and in water [31-33]). Vehicle and no treatment controls were included in both experiments, and an adult treatment comparison group was included in experiment 2 . In both experiments, $24 \mathrm{~h}$ after the last treatment day, anxiety-like behavior was evaluated using the elevated plus maze and after another $24 \mathrm{~h}$, depressive behavior was evaluated using the forced swim test, both well validated measures (reviewed in [34,35]). In experiment 2, blood samples were obtained at timepoints after the end of the forced swim test to evaluate treatment effects on stress-induced corticosterone release. The aim of the experiments was to assess the potential of exogenous corticosterone as a model for adolescent mood disorders. The main hypothesis of both experiments was that chronic treatment with exogenous corticosterone in adolescence would increase anxiety-like and depressive behavior in rats.

\section{Methods}

Experiment 1

Animals

Male Long-Evans rats $(\mathrm{n}=24)$ were obtained from Charles River (St Constant, Quebec, Canada) at 22 days of age. Rats were housed in pairs in polycarbonate cages and were provided with a plastic tube in each cage for enrichment throughout the experiment. Rats were identified by tail coloring with a felt tip marker. The rats were kept on a $12 \mathrm{~h}$ light, $12 \mathrm{~h}$ dark light cycle, and were given unlimited access to rat chow and water. All experimental procedures were consistent with National Institutes of Health Guide for Care and Use of Laboratory Animals (Publication No. 85-23, revised 1985), and Canadian Council on Animal Care guidelines and were approved by the Brock University Institutional Animal Care and Use Committee.

\section{Treatment}

Starting on postnatal day 30, rats were randomly assigned to one of three treatment conditions. The CORT group $(\mathrm{n}=8)$ was given a daily injection subcutaneously for 16 days of $40 \mathrm{mg} / \mathrm{kg} / \mathrm{ml}$ corticosterone (Steraloids, Newport, RI, USA) (procedure as in [36,37]) suspended in isotonic saline and 2\% Tween 80 (SigmaAldrich, St Louis, MO, USA). The VEHIC group ( $\mathrm{n}=8$ ) was injected daily with vehicle for 16 days. After 
injection, the rat was returned to the home cage, and each pair of rats that shared a cage was administered the same treatment. Previous research has found this dose of corticosterone injection to produce plasma corticosterone levels of approximately 2,100 $\mathrm{ng} / \mathrm{ml} \mathrm{1-4} \mathrm{h}$ after the injection [37]. The rats were weighed once every 3 days, and the injection volume was adjusted accordingly. The NO-INJ (no injection, $\mathrm{n}=8$ ) control group was not disturbed except for cage maintenance and was weighed only on postnatal days 30 and 45 (first and last injection days). Rats were tested in the elevated plus maze on postnatal day 46 and in the forced swim test on postnatal day 47 .

\section{Elevated plus maze}

The elevated plus maze (EPM), first described by Pellow and colleagues [38], is a well validated measure of anxiety in rodents [34]. The EPM relies on conflict between the propensity of rodents to explore novel territory and their fear of open and elevated areas. The EPM consisted of four arms $50 \mathrm{~cm}$ in length, and walls enclosing two arms (closed arms) $42 \mathrm{~cm}$ in height constructed out of grey painted plywood. The sides of the open arms had $1.3 \mathrm{~cm}$ high ledges. The maze was raised $79 \mathrm{~cm}$ off the ground and was kept in a separate room from the colony. During testing, the maze was illuminated with dim white light and white noise (approximately $60 \mathrm{~dB}$ ) was played. Each rat was placed in the closed arm at the end farthest from the center and was allowed to explore the maze for $5 \mathrm{~min}$. All sessions were videotaped, and tapes were later scored while blind to treatment condition. Tapes were scored for time spent in the open arm (with more time on the open arm, higher percent time on open arm, and higher percentage of open arm entries all indicative of less anxiety) and center hub as well as the total number of entries into closed arms (used as an index of locomotor activity), rears (when the rat stands on its hind legs) and head dips (when the rat reaches its head over the edge of the open arm). Rears and dips are considered measures of exploratory behavior that are exhibited more when less anxious.

\section{Forced swim test}

The forced swim test (FST) is a measure of behavioral despair (for example, [39]) and consisted of a clear cylinder $20.3 \mathrm{~cm}$ in diameter filled $24.1 \mathrm{~cm}$ high with water such that a rat was unable to touch the bottom or climb over the side. The water was warmed to $26^{\circ} \mathrm{C}$, and it was changed for each rat. Rats were placed in the water and left in the tank for 15 min in experiment 1 and $20 \mathrm{~min}$ in experiment 2 (longer time in experiment 2 was used for maximal corticosterone release). All sessions were videotaped, and tapes were later scored while blind to treatment condition. Behavioral measures for analysis were derived from the literature (for example, $[40,41])$ and included the following four behaviors: swimming (quick movements of forelimbs and/or hindlimbs, including swimming in circles and pedaling), climbing (in a vertical position, pawing at the side of the cylinder with front paws and leveraging the body slightly out of the water), diving (head under water, swimming to the bottom of cylinder, including circling at the bottom) and immobility (reduced movement including floating and slow circling or pedaling). Diving occurred with very low frequency, and was thus not included in statistical analyses. Climbing reflects the most vigorous attempt at escape whereas immobility is the measure considered to represent depressive-like behavior.

Classically the FST is administered in two sessions that are $24 \mathrm{~h}$ apart, with latency to immobility and time spent immobile measured in the second session and the first session considered the means to induce a depressive state (for example, [39]). However, stressors or chronic manipulations are found to produce depressionlike states and thus differences among groups can be found in the first session (for example, $[28,36,42]$ ). Further, the effects of chronic corticosterone treatment for 21 days in adults were the same whether tested with a 1 day version of the test or a 2 day version [29]. Therefore, the experiments described here used a onesession test.

\section{Experiment 2}

\section{Animals, treatment, and procedure}

Male Long-Evans rats were obtained from Charles River at 22 days of age $(n=20)$ or at 64 days of age $(n=20)$ and were housed in age-matched pairs as in experiment 1. Starting on postnatal day 30 or 70 , the drinking water was replaced for the CORT-ETOH rats $(\mathrm{n}=8$ per age group) with a solution of $400 \mu \mathrm{g} / \mathrm{ml}$ corticosterone (Steraloids) dissolved in $2.5 \%$ ethanol. To ensure that any effects observed were the result of corticosterone treatment and not ethanol exposure, a second group was given $2.5 \%$ ethanol to drink (ETOH rats, $n=6$ per group). The WATER rats ( $\mathrm{n}=6$ per group) continued to receive tap water. Each solution was colored with a different food coloring to be easily distinguished from one another. After 16 days, on postnatal day 46 or 86 , treatment was removed and tap water was provided to all. During treatment, the mass of water consumed was measured every 2 days. Rats were weighed before and after the 16 days of treatment, but were not handled during the course of treatment, except for cage cleaning thrice weekly. Using weight at the start and end of treatment, the dose of ethanol and of corticosterone consumed by the pair of rats in a cage over a 2 day period was calculated. To calculate the doses of ethanol and corticosterone, the density of each solution was determined by weighing $1 \mathrm{ml}$ of each solution, because consumption was measured in mass. Using the beginning 
and ending weights, the approximate weight on day 8 of treatment was extrapolated, and the ethanol and corticosterone doses for days 7 and 8 were calculated based on this weight. All rats in this experiment were tested on the EPM on either postnatal day 46 or 47 and on the FST on postnatal day 47 or 87 using the methods described for experiment 1 .

\section{Collection and measurement of plasma corticosterone}

To determine the amount of corticosterone released after the FST, blood was collected by tail nick from each rat immediately, $45 \mathrm{~min}$ and $90 \mathrm{~min}$ after removal from the test. No baseline was obtained before the FST in order that behavior in the FST would not be affected by the blood sampling. Blood samples were centrifuged at $3,000 \mathrm{rpm}$ and $4^{\circ} \mathrm{C}$ for $20 \mathrm{~min}$. Plasma was collected and stored at $-20^{\circ} \mathrm{C}$ until corticosterone was measured using enzyme-linked immunosorbent assay kits (Neogen, Lansing, MI, USA). Corticosterone was extracted from the samples using ethyl ether and the samples were reconstituted in a buffer provided in the kit. The assay was run entirely as specified in the instructions for the kit, except that the reconstituted samples were diluted twofold compared to the kit instructions in order for the stress levels of corticosterone to be readable within the standard curve. The minimum detection level for the assay is $1 \mu \mathrm{g}$ per tube. The antiserum crossreacts with deoxycorticosterone (38\%), and only slightly with cortisol $(1.1 \%)$, testosterone $(0.12 \%)$, and estradiol $(<0.01 \%)$. The intra-assay and interassay reliabilities were both less than $10 \%$.

\section{Results and discussion \\ Experiment 1 \\ Weight}

There were no group differences in weight on postnatal day $30\left(\mathrm{~F}_{1,21}=0.02, P=0.93\right)$, but by postnatal day 45 , corticosterone injected (CORT) rats weighed less than vehicle injected (VEHIC) and no injection (NO-INJ) rats $\left(\mathrm{F}_{1,21}=10.78, P=0.001\right.$, see Figure 1$)$. The finding of reduced weight gain of CORT rats is consistent with the evidence of reduced weight gain or weight loss after exogenous corticosterone treatment in adult rats (for example, $[28,36])$ and after chronic stressors in adolescent and in adult rats (for example, [43-45]).

\section{EPM}

Although vehicle injection had no effect on weight gain, both VEHIC and CORT treated rats had increased anxiety-like behavior compared to NO-INJ rats. NO-INJ rats spent more time on the open arm $\left(\mathrm{F}_{1,21}=7.96, P=\right.$ 0.003 , see Figure 2$)$ than $\operatorname{did} \operatorname{VEHIC}(P=0.002)$ and CORT $(P=0.002)$ rats, which did not differ $(P=0.78)$. The same pattern of significant differences as time in the open arm were obtained for the percentage of time in the open arm using time in open and closed arms

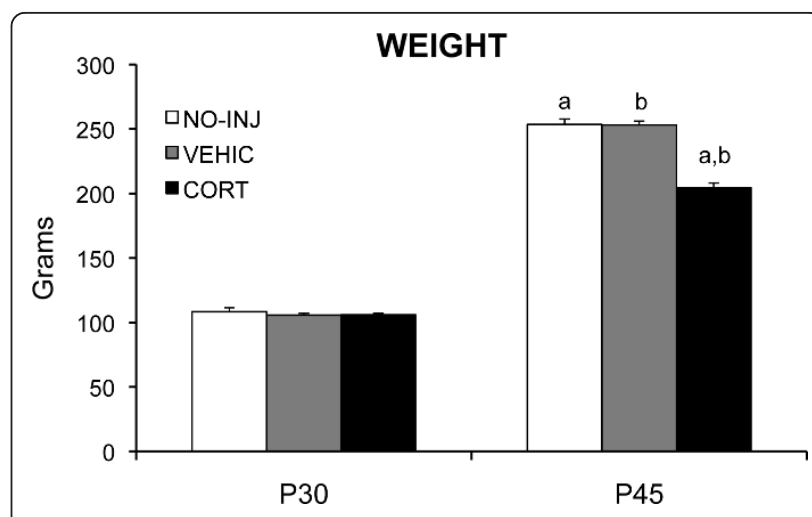

Figure 1 Mean (SEM) weight at postnatal day 30 (P30) and $\mathrm{P} 45$, the first and last day of treatment for the corticosterone injected (CORT), vehicle injected (VEHIC) and no injection (NOINJ) groups. Matched letters indicate significant $(P<0.05)$

differences between groups.

without time in the hub as a denominator $\left(\mathrm{F}_{1,21}=7.96\right.$, $P=0.003$, (mean, \pm SEM) $=$ VEHIC rats $(6.4 \%, \pm 2.6)$, CORT rats $(7.6 \%, \pm 1.6)$, and NO-INJ rats $(23.7 \%, \pm$ 5.0)). Differences were less marked using percentage of open arm entries relative to total arm entries as the index of anxiety $\left(\mathrm{F}_{1,21}=3.65, P=0.045\right.$, with only VEHIC rats having a lower percentage of open arm entries $(20.8 \%, \pm 6.8)$ than NO-INJ rats $(37.7 \%, \pm 2.75)$, and neither group different from CORT rats $(29.8 \%, \pm$ 1.9)). NO-INJ rats reared and head dipped more than did VEHIC and CORT rats, which did not differ $\left(\mathrm{F}_{1,21}=\right.$ 32.45, $P<0.0001, \mathrm{~F}_{1,21}=10.41, P<0.0001, \mathrm{~F}_{1,21}=4.76$, $P=0.02$, see Figure 2 ). The differences among the groups in time spent in the hub of the EPM and the number of closed arm entries were not significant $\left(\mathrm{F}_{1,21}\right.$ $=2.72, P=0.09$ and $\left.\mathrm{F}_{1,21}=3.11, P=0.07\right)$.

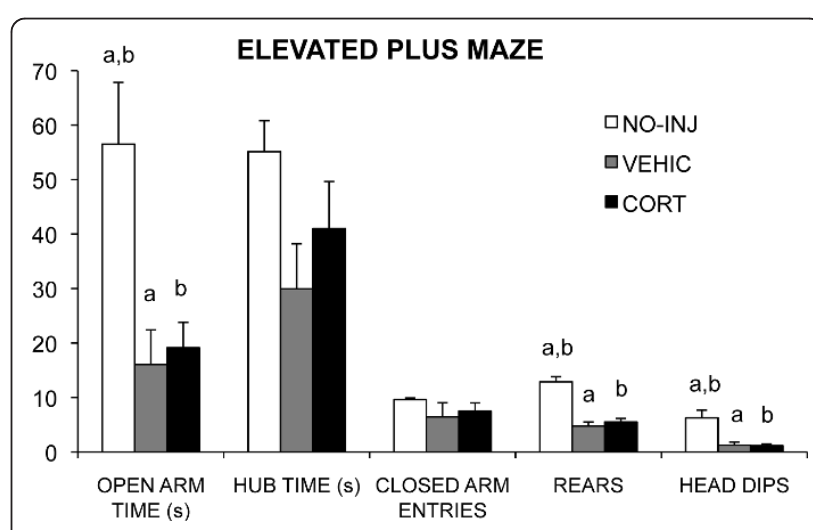

Figure 2 Mean (SEM) of the behavioral measures for the elevated plus maze (EPM) for corticosterone injected (CORT), vehicle injected (VEHIC) and no injection (NO-INJ) groups. Matched letters indicate significant $(P<0.05)$ differences between groups within each behavioral measure. 
These results suggest that stress of injection is sufficient in adolescence to increase anxiety-like behavior. Although acute injections are known to be a mild stressor (for example, [46]), adult rodents readily habituate to repeated injections (for example, $[47,48]$ ). Further, in studies of adults, even when a higher number of injections were used than the 16 used here, differences are observed between vehicle-treated and corticosteronetreated groups $[28,29,36,49]$. Thus, adolescents may be more sensitive to injection stress than are adults.

\section{FST}

There was no main effect or interaction of group and time on climbing or immobility (all $P>0.19$ ) (see Figure $3)$. The interaction of group and time on swimming approached significance $\left(\mathrm{F}_{4,42}=2.48, P=0.06\right)$. The three groups did not differ in latency to immobility $(P=$ 0.72 , data not shown). To explore the possibility that group differences were masked by low power by inclusion of several timepoints in the analysis (shorter times than 15 min have been used for analysis by others, for example [29]), a multivariate analysis of variance (MANOVA) was computed for climbing, immobility, and swimming, using only the first $5 \mathrm{~min}$ in the FST. The multivariate test of group was significant (Pillai's trace $\left.\mathrm{F}_{6,40}=2.73, P=0.025\right)$, with significant between subject effects for immobility $\left(\mathrm{F}_{2,21}=4.32, P=0.027\right)$ and for swimming $\left(\mathrm{F}_{2,21}=6.78, P=0.005\right)$. Post hoc analyses indicated that CORT rats spent less time immobile and more time swimming than did NO-INJ rats and more time swimming than VEHIC rats (all $P<0.05$ ) (see Figure 3).

Thus, the effects of treatment were limited to the first 5 min of the test and were in the opposite direction than predicted. The measure of depressive behavior in the FST is immobility, and thus CORT rats showed less depressive behavior than did NO-INJ rats. The VEHIC rats' behavior fell between that of the CORT and NOINJ rats. An alternative explanation is that the increased swimming and decreased immobility of CORT rats is a reflection of their increased anxiety evident in the EPM. Anxiety symptoms are as common as depressed mood is among people meeting the criteria for major depressive disorder [50], and there is evidence that anxiety may be a precursor for the development of depression [51]. Nevertheless, there is increasing evidence of both shared and distinct neural mechanisms underlying anxiety and depressive behaviors (for example, [52]).

Others also have reported the apparent contradiction of increased anxiety and decreased depressive behaviors in animal models. For example, knockout (KO) mice for the 5-hydroxytryptamine $(5 \mathrm{HT})_{1 \mathrm{~A}}$ receptor also exhibited increased anxiety in an open field test and increased swimming and decreased immobility in the FST [53]. The authors interpreted the behavior in the FST as
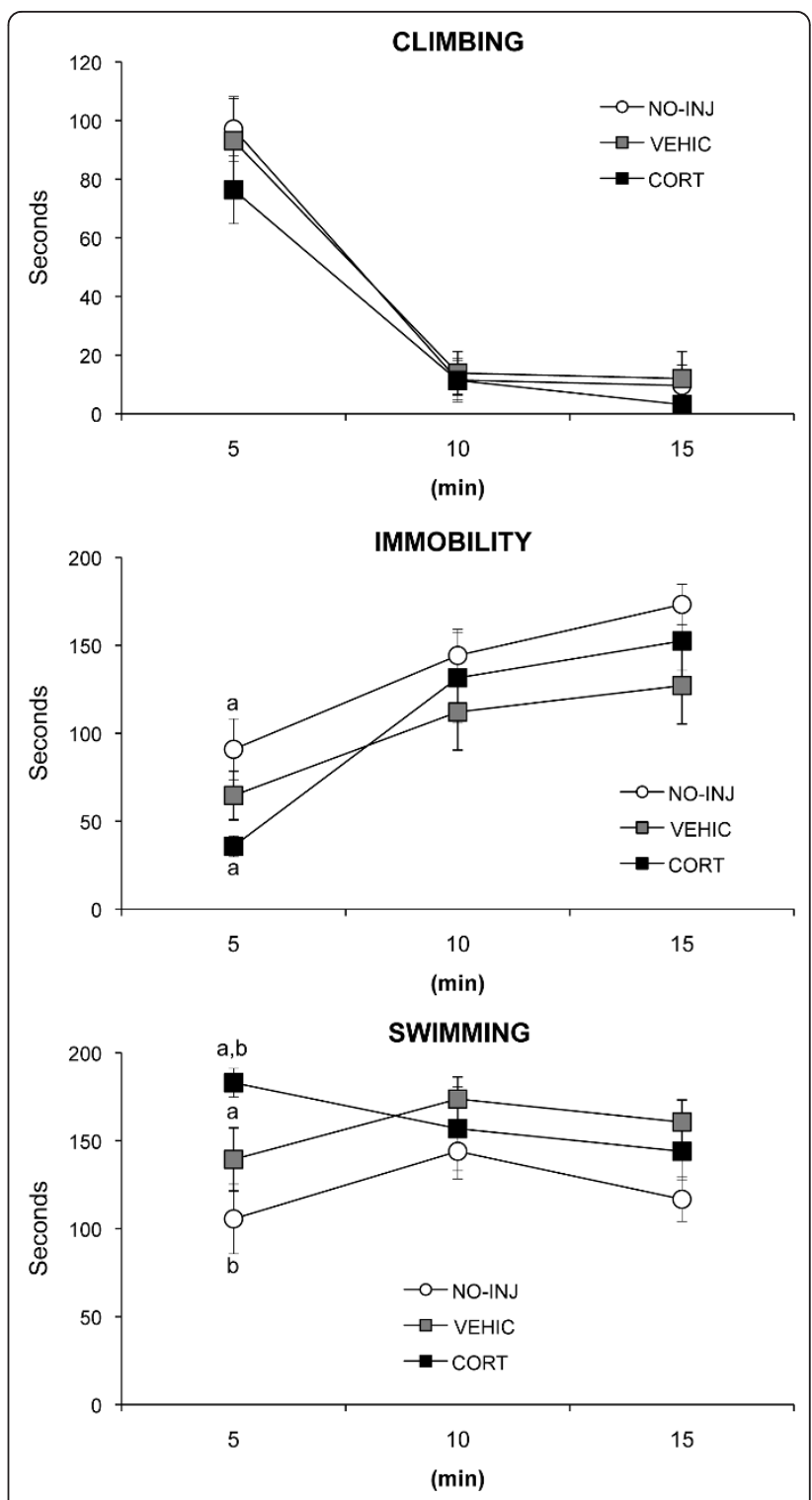

Figure 3 Mean (SEM) of the behavioral measures for the forced swim test (FST) for corticosterone injected (CORT), vehicle injected (VEHIC) and no injection (NO-INJ) groups. Matched letters indicate significant $(P<0.05)$ differences between groups within each behavioral measure.

further evidence of increased anxiety and emotional reactivity rather than to decreased depression, and they suggested the differences in $\mathrm{KO}$ mice might involve increased serotonergic turnover. More recently, $\mathrm{KO}$ mice of the $5 \mathrm{HT}_{1 \mathrm{~A}}$ autoreceptor had increased anxiety and did not differ from controls in the FST, whereas $\mathrm{KO}$ mice of the $5 \mathrm{HT}_{1 \mathrm{~A}}$ heteroreceptor had increased immobility in the FST and did not differ in anxiety from controls [52]. In adults, chronic injection of corticosterone decreases neural responsiveness to serotonin (for example, [54]) and increases depressive behavior in the 
FST (for example, $[28,29,36]$ ). One possibility for the difference in the results of the previous studies in adults whereby injection of corticosterone increased depressive behavior compared to our finding of reduced depressive behavior (or increased anxiety) for adolescents is that our study involved fewer injections than those in studies of adults (16 versus 21 injections). A stronger possibility is that the differences between the studies of adults and ours with adolescents are because of developmental differences in susceptibility to the effects of stress/corticosterone. Studies of adults have found more robust differences between vehicle injected and corticosterone injected groups, thus adults may be less susceptible to injection stress than are adolescents. The ongoing maturation of neural circuitry underlying emotional behavior, which is evident, for example, in the different responses of adolescent and adult rats to selective serotonin reuptake inhibitors (for example, [55]), may render the circuitry more vulnerable.

In experiment 2, we eliminated the possibility of stress of injection by administering corticosterone in the drinking water. The method, which involves dissolving corticosterone in ethanol, was based on established procedures that have effectively mimicked many of the effects of chronic stress in adult rats (for example, [31-33]). Because the comparable studies available were conducted only in adults, we were concerned that ethanol alone may have an effect in adolescents. Thus, two control groups were used, one group was given $2.5 \%$ ethanol to drink and the other was given water only. To better assess the specificity of effects to developmental stage, an additional three experimental groups received treatment in adulthood.

\section{Experiment 2}

\section{Weight}

There were no group differences in weight on postnatal day $30\left(\mathrm{~F}_{1,17}=0.54, P=0.93\right)$, but by the 16 th day of treatment on postnatal day 45, CORT-ETOH rats had gained less weight than ETOH and WATER rats, which did not differ $\left(\mathrm{F}_{1,17}=4.37, P=0.029\right.$, see Figure 4$)$. There were no weight differences for the adult groups on the first day of treatment $\left(F_{1,17}=2.84, P=0.09\right)$, but by the 16 th day of treatment, CORT-ETOH rats had gained less weight than ETOH and WATER rats, which did not differ $\left(F_{1,17}=13.85, P<0.0001\right.$, see Figure 4$)$. Thus, the effects of corticosterone treatment in the drinking water were similar to the results in other studies (for example, $[31,56]$ ) and to the effect of corticosterone injection in experiment 1 , and the effects were comparable for adolescents and adults. No effect of $2.5 \%$ ethanol was observed on weight.

\section{Intake}

Treatment altered the intake of the three groups differently for adolescents than for adults. For adolescents, there was an interaction of treatment day and group $\left(\mathrm{F}_{2,14}=3.25, P=0.04\right)$ : The intake of CORT-ETOH rats was less than that of ETOH rats $(P=0.01)$ and less than that of WATER rats on day 16 of treatment $(P<$ 0.0001) (see Figure 5a). For adults, although the intake of CORT-ETOH rats was less than that of the other groups, only the effect of treatment day was significant $\left(\mathrm{F}_{2,14}=6.42, P=0.01\right)$, whereby intake increased over days (see Figure $5 \mathrm{~b}$ ). Thus for adults, there seemed to be an immediate aversion to corticosterone that reduced intake throughout, whereas in adolescents, corticosterone did not reduce drinking initially. The reduced

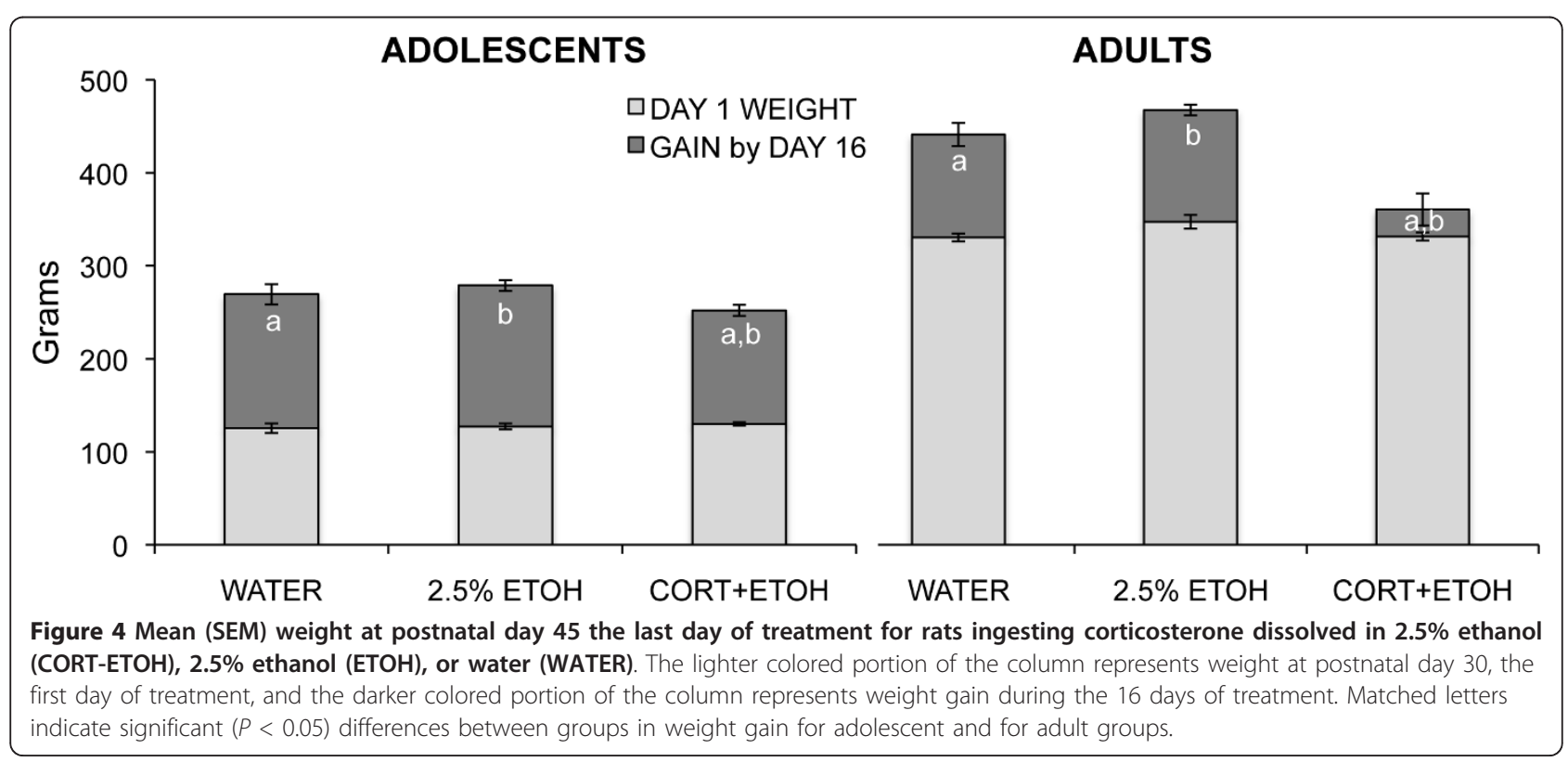




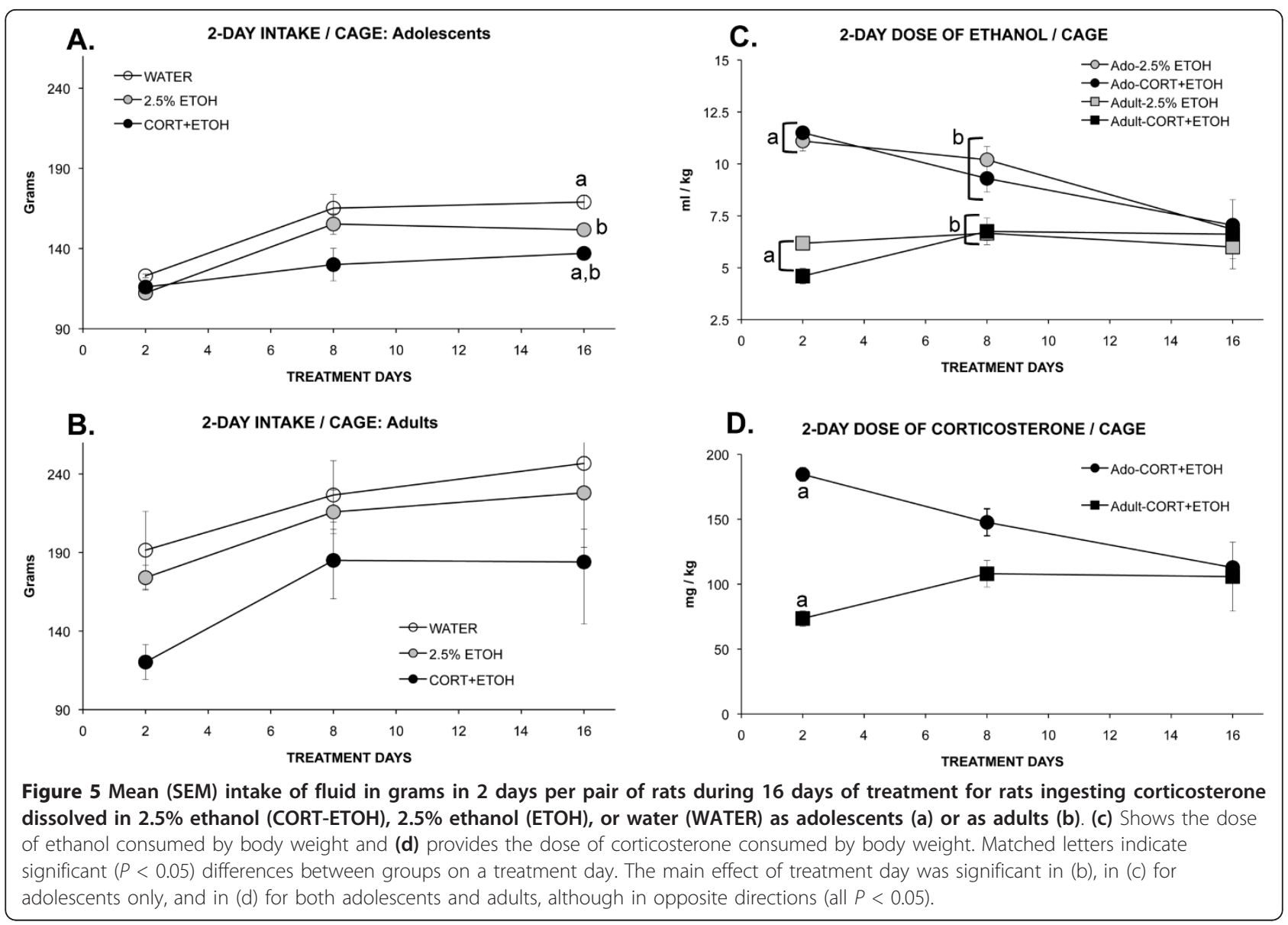

drinking by day 16 of CORT-ETOH adolescent rats may be related to their reduced body weight or to an aversion that was slower to develop. For neither age group was the intake of rats drinking $2.5 \%$ ethanol different from those rats drinking water only.

The interaction of treatment day and age was significant for the dose of ethanol consumed $(\mathrm{ml} / \mathrm{kg})\left(\mathrm{F}_{2,14}=\right.$ 15.99, $P<0.0001)$ : For adolescents, the dose of ethanol consumed $(\mathrm{ml} / \mathrm{kg})$ decreased over treatment days $\left(\mathrm{F}_{2,10}\right.$ $=84.95, P<0.0001)$ similarly for the CORT-ETOH and ETOH rats (see Figure 5c). For adults, there was no effect of, or interaction of, treatment day and group. The higher dose of ethanol ingested by adolescents than by adults was significant only at treatment day 2 and 8 (both $P<0.0001)$. The interaction of age $\times$ treatment day was significant for the dose of corticosterone $(\mathrm{mg} /$ $\mathrm{kg})$ consumed by the CORT-ETOH groups $\left(\mathrm{F}_{2,14}=6.42\right.$, $P=0.01)$ : For adolescents, the dose of corticosterone $(\mathrm{mg} / \mathrm{kg})$ consumed by the CORT-ETOH rats declined over time $\left(\mathrm{F}_{2,6}=309.3, P<0.0001\right)$, and for adults $\left(\mathrm{F}_{2,6}\right.$ $=91.5, P<0.0001)$, the dose of corticosterone $(\mathrm{mg} / \mathrm{kg})$ consumed increased over time (see Figure $5 \mathrm{~d}$ ). The higher dose of corticosterone ingested by adolescents than by adults was significant only at treatment day $2(P$ $=0.02$ ). These results highlight the difficulty in administering comparable dosages in drinking water to rats of different stages of development.

\section{EPM and FST}

There were no differences among the groups for any of the EPM measures for either adolescents (all $P>0.32$ ) or adults (all $P>0.13$ ). Adolescents spent less time in the center hub than did adults, but no other age difference was significant $\left(\mathrm{F}_{1,34}=4.26, P=0.047\right)$ (see Figure $6)$. Although there was effect of time for the FST measures, with climbing and swimming decreasing and immobility increasing with time for both age groups (see Figure 7 ), the only effect of group was a group $x$ time interaction $\left(\mathrm{F}_{6,51}=2.63, P=0.027\right)$ for time spent climbing by adults. No group comparison, however, was significant at any timepoint.

There are several possibilities for the lack of an effect of corticosterone treatment on anxiety-like and depressive behavior when administered in the drinking water compared to when injected. One possibility is that we would have uncovered behavioral differences among the groups using a broader range of tests of anxiety-like and 


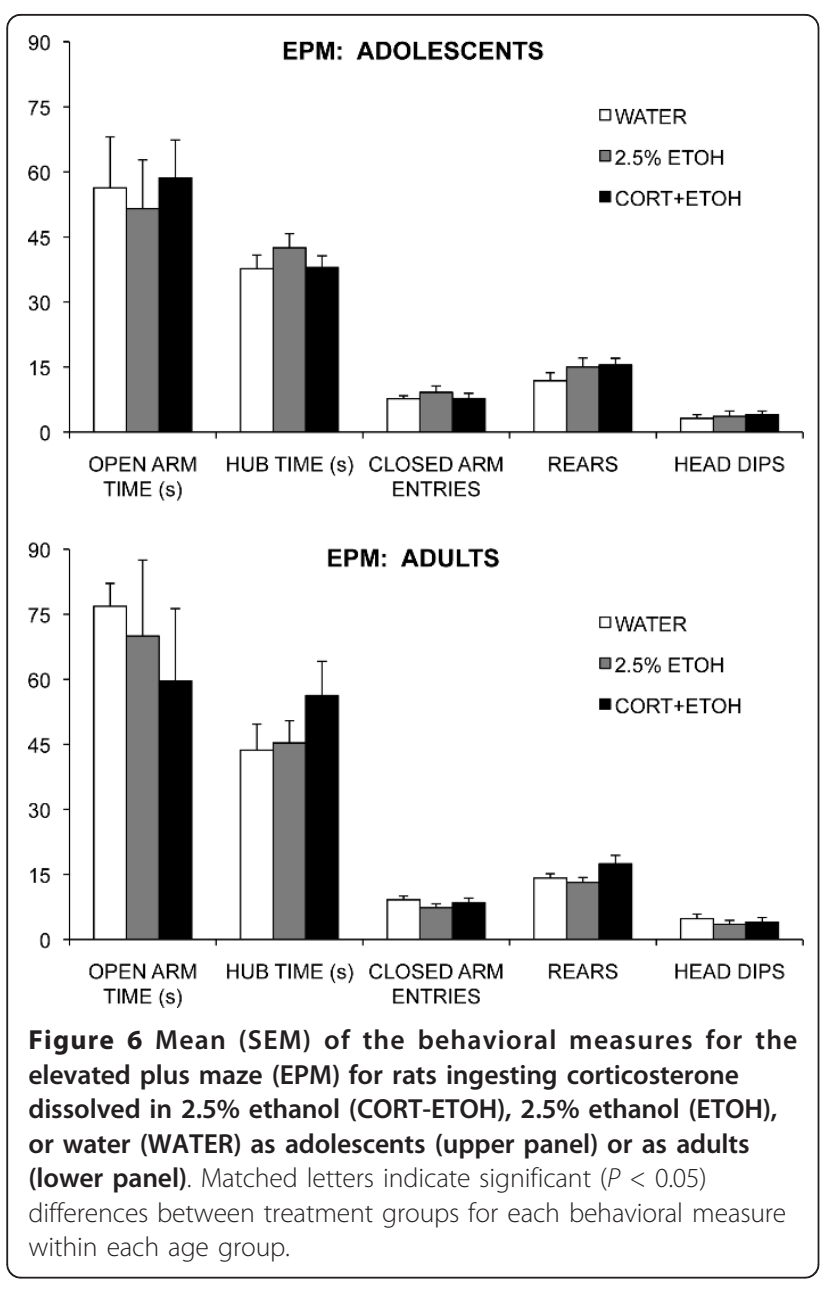

depressive behavior. Another possibility is that, at least in adolescence, corticosterone is not as effective at altering emotional behavior in the absence of actual stressful experiences, such as injection. Of note, in experiment 1 , the effect of injection of corticosterone on behavior was only marginally greater than that of injection of vehicle. Exogenous corticosterone and chronic stress do not always have the same effects when directly compared. Although both 21 days of $400 \mu \mathrm{g} / \mathrm{ml}$ corticosterone in drinking water and 21 days of chronic stress (restraint 6 $\mathrm{h} /$ day) caused retraction of hippocampal dendrites, only chronic stress impaired spatial memory [57], and the two manipulations differed in their effects on fear conditioning [33] and had the opposite effects on proteins involved in synaptic plasticity in the piriform cortex [58]. Whereas 21 days of injection of corticosterone decreased the number of cells expressing reelin in the hippocampus, 21 days of daily restraint did not [59]. Nevertheless, the differential effects of chronic stress versus exogenous administration of corticosterone do not explain the absence of an effect of corticosterone observed in experiment 2.
Another possibility is that 16 days is insufficient to have an effect with $400 \mu \mathrm{g} / \mathrm{ml}$ in the drinking water, especially when the pharmacokinetics of this method of delivery differs from a bolus injection, which is more similar to that produced by a bout of restraint. Consistent with the possibility that dose may be a factor is that injections of $10 \mathrm{mg} / \mathrm{kg}$ corticosterone in adult rats are sufficient to cause dendritic retraction in the hippocampus (for example, $[60,61]$ ) but higher doses are required to increase depressive behavior in the FST [28]. Lastly, the evidence for an effect of corticosterone delivered in the drinking water on anxiety and depressive behavior is not as substantial as it is for corticosterone delivered by injection. The available studies used mice rather than rats and lower doses $(<50 \mu \mathrm{g} / \mathrm{ml})$ and found reduced depressive behavior when provided for 1 to 4 days [62], increased depressive behavior when provided for 14 days and tested 2 weeks later [63], but did not affect depressive behavior in the FST when provided for 4 weeks [64]. Thus, given the advantages of administering corticosterone in the drinking water (for example, no handling or injection of the animals is involved), it would be worthwhile to test the effects of the $400 \mu \mathrm{g} / \mathrm{ml}$ dose provided over a longer time frame on behavior.

\section{Plasma corticosterone}

Baseline samples were not collected before the FST to prevent interference with subsequent behavior. Plasma concentrations of corticosterone obtained at timepoints after the FST indicated that both corticosterone treatment and the $2.5 \%$ ethanol vehicle altered HPA function. For adolescents, the interaction of sampling time and group was significant $\left(\mathrm{F}_{4,34}=5.73, P=0.001\right)$ (see Figure 8). At removal from the FST and 45 min later, CORT-ETOH rats had lower corticosterone concentrations than had WATER rats (both $P<0.0001$ ). ETOH rats had lower corticosterone concentrations than had WATER rats only immediately after removal from the FST $(P=0.001)$. Group differences were not significant 90 min after the FST.

For adults, the interaction of sampling time and group was significant $\left(\mathrm{F}_{4,34}=16.55, P<0.0001\right)$ (see Figure 8). On removal from the FST and 45 min later, CORTETOH rats had lower corticosterone concentrations than had ETOH (both $P<0.0001$ ) and WATER rats (both $P<0.01$ ), and ETOH rats had higher corticosterone concentrations than had WATER rats (both $P<$ 0.05). The groups did not differ $90 \mathrm{~min}$ after the FST.

Reduced adrenal function after lengthy exogenous treatment with high doses of corticosterone is a typical finding, because of the reduction in size of the adrenal gland caused by exogenous corticosterone, which is in contrast to the increase in size of the adrenal produced by chronic stress (for example, $[28,31]$ ). Thus, the lack of effect of treatment on behavior cannot be attributed 

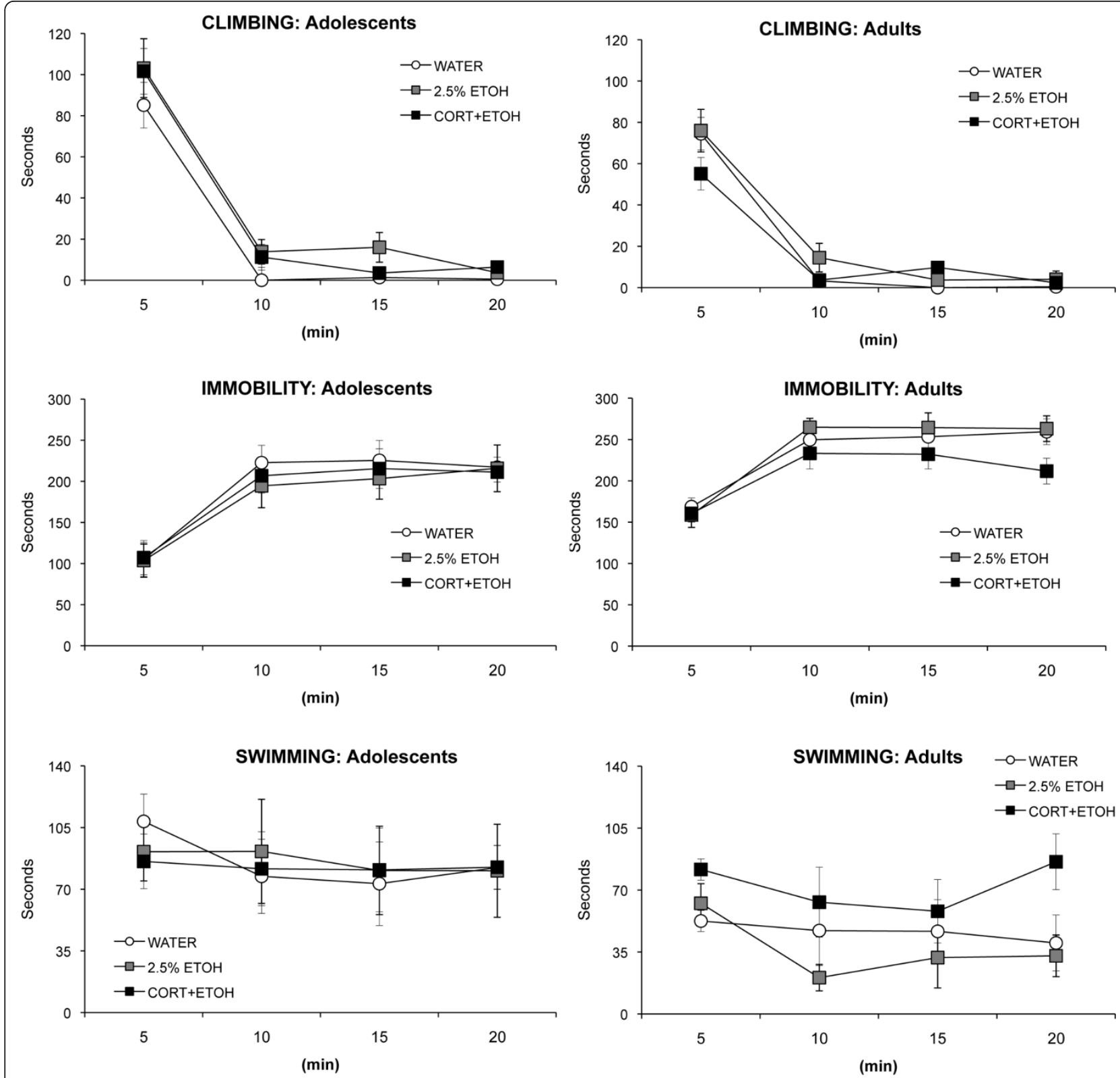

Figure 7 Mean (SEM) of the behavioral measures for the behavioral measures for the forced swim test (FST) for rats ingesting corticosterone dissolved in $2.5 \%$ ethanol (CORT-ETOH), $2.5 \%$ ethanol (ETOH), or water (WATER) as adolescents (left panels) or as adults (right panels).

to a lack of delivery of the treatment. The effect of $2.5 \%$ ethanol vehicle on corticosterone release was unexpected, as most studies of corticosterone in the drinking water have not included a 'no $2.5 \%$ ethanol' control group (for example, $[33,56,58,65]$ ). In adolescents, the low dose of ethanol in the drinking water reduced corticosterone release after the FST, but not to the same extent that corticosterone and ethanol combined did. In adults, ethanol prolonged corticosterone release after the FST. Whether the effect of ethanol involved effects on the adrenal gland or at a higher level of control of the HPA axis in either adolescents or adults is unknown. After acute or chronic ethanol exposure to adult rodents, usually heightened HPA function is reported, with changes evident at all levels of the HPA axis (such as increased adrenal weight/corticosterone content, higher expression of pituitary pro-opiomelanocortin (POMC) mRNA, of hypothalamic corticotropinreleasing hormone (CRH) mRNA) that are consistent with higher stress-induced corticosterone release (for 

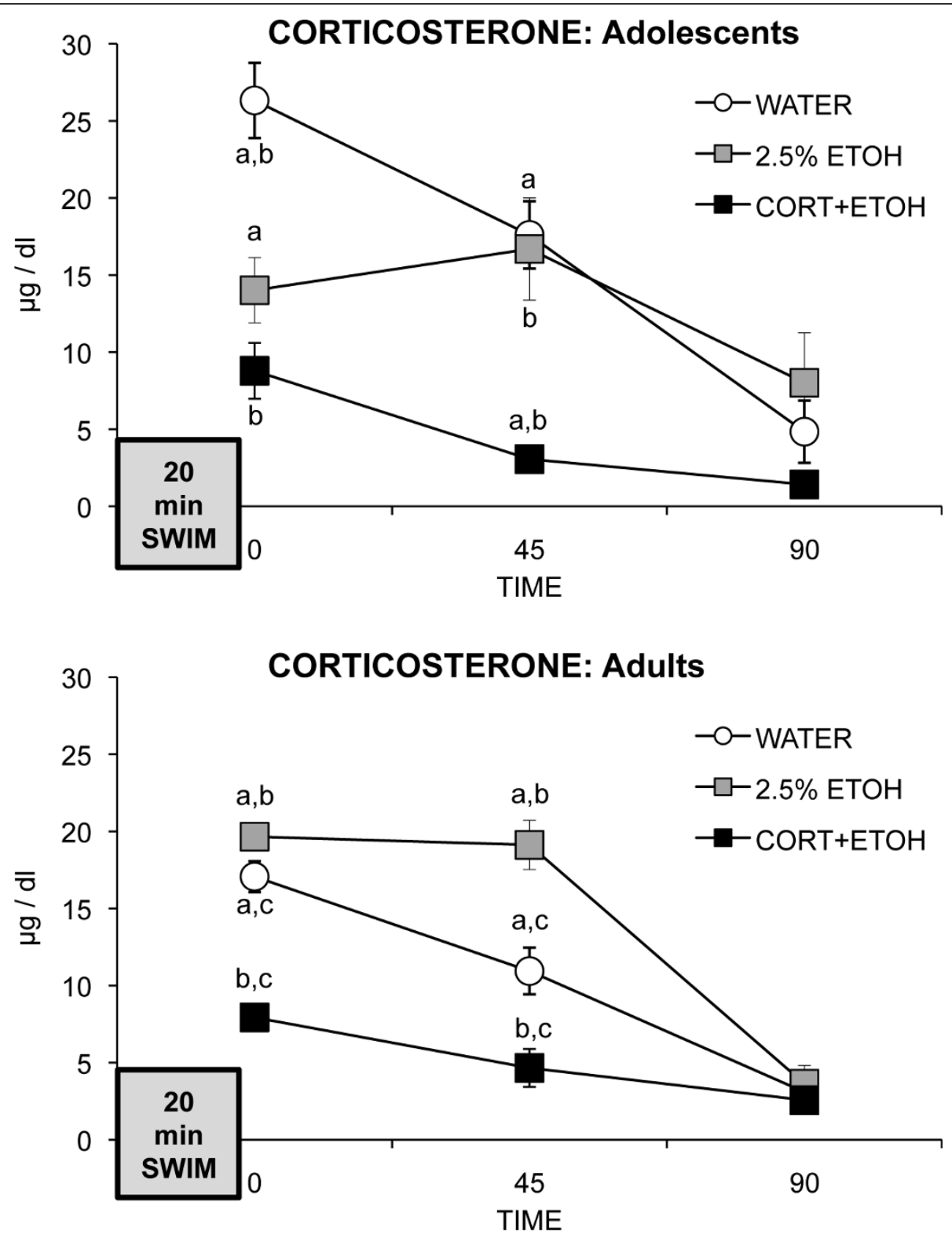

Figure 8 Mean (SEM) concentrations of corticosterone at timepoints after removal from the forced swim test (FST) for rats ingesting corticosterone dissolved in $2.5 \%$ ethanol (CORT-ETOH), $2.5 \%$ ethanol (ETOH), or water (WATER) as adolescents (upper panel) or as adults (lower panel). Matched letters indicate significant $(P<0.05)$ differences between treatment groups at a timepoint within each age group.

example, [66-70] although for evidence of dampened HPA function after alcohol exposure, see [71]).

The differences in the effects of ethanol in the two age groups may reflect differences in their developmental stage (for example, [72]) or that the dose of ethanol consumed was higher for adolescents than for adults. In adults, although activation of the HPA axis was found to a first dose of alcohol, self-administration or experimenter administration of alcohol was found to dampen HPA responses to subsequent stressors up to 24 days after removal of the alcohol (reviewed in [71]). One study of adolescent exposure to ethanol (alcohol vapors) found evidence of reduced HPA function when tested in adults [73]. In contrast, binge drinking ( $3 \mathrm{~g} / \mathrm{kg} /$ day) beginning at postnatal day 37 increased the expression of secretagogues of ACTH in the paraventricular nucleus of the hypothalamus in adolescence [74]. Such studies, however, involved much higher doses than used here (for example, a bolus injection of $4.5 \mathrm{mg} / \mathrm{kg}$ to a rat is far more than the $200 \mathrm{mg} / \mathrm{kg}$ highest dose 
consumed by a pair of rats over a $48 \mathrm{~h}$ period in the present study). Nevertheless, the present results suggest that a no vehicle control group should be used in future studies using ethanol as a vehicle for corticosterone.

\section{Conclusions}

Administration of exogenous corticosterone has proven to be an effective preclinical model of depression in adult rodents to study the relationships among stress, glucocorticoids, and depression (reviewed in [14]). The findings of the present experiments suggest there are challenges to overcome in the use of exogenous corticosterone to investigate the heightened vulnerability of adolescents to stressors. First, the stress of injection masks potential effects of exogenous corticosterone in adolescents, whereas robust differences between vehicleinjected and corticosterone-injected subjects are found routinely in adults [14]. Second, corticosterone delivered in the drinking water does not allow for sufficient control of dosing for comparable treatment in adolescents and adults. Administration procedures that do not involve ethanol, such as the use of corticosterone hemisuccinate rather than corticosterone, are recommended, because even the low dose of ethanol used here affected corticosterone release in both adolescents and adults. Further, although the dose of corticosterone used (400 $\mu \mathrm{g} / \mathrm{ml}$ ) represents the high end of doses administered in such a way, 16 days of treatment did not produce effects on behavior in the EPM and the FST, although many studies have found chronic stress in adolescence to affect behavior in the EPM and the FST within shorter timeframes (reviewed in [13]). Thus, although this route of administration overcomes the problem of stress of injection, the more sustained pattern of corticosterone exposure through such oral administration may not allow for marked effects on mood-related behavior to be observed in rats. In sum, the present results highlight challenges to overcome in the use of exogenous corticosterone treatments in animal models to study sensitivity to stress and mood disorders in adolescence.

Clinicians have long recognized there are unique features to mood disorders in adolescence compared to in adulthood, irrespective of whether or not a mood disorder is the same fundamental disease at each age (for example, [75]). In humans, anxiety is primarily a disorder of childhood and adolescence, with anxiety in adults stemming from adolescence, and stress is a risk factor for anxiety in adolescence $[76,77]$. Immaturity of the relevant regulatory mechanisms in adolescence is thought to underlie the difference in performance on behavioral tests of anxiety of adolescent and adult rats $[78,79]$. In experiment 1 , injected and corticosteronetreated adolescents had increased anxiety-like behavior compared to control rats, with little difference observed in depressive behavior. Similar treatments in adult rats found greater increases in depressive behavior than in anxiety [14]. These results suggest there are age differences in the behavioral expression of exposure to corticosterone that may parallel the developmental stagespecific manifestations of mood disorders in humans. In humans, the age of onset for depression is later than for anxiety, which also suggests that the maturation of relevant neural circuitries may determine which mood disorder or symptom is evident at each age. These points underscore the relevance of animal models for understanding the pathogenesis of mood disorders and the importance of investigating the range of developmental stages in both preclinical and clinical studies.

\section{Acknowledgements}

The research was completed in partial fulfillment of the requirements for the Master of Arts degree (PW). The research was supported by grants from the Natural Sciences and Engineering Research Council, the Canadian Foundation for Innovation, and the Ontario Innovation Trust (CMM). We thank Feather Nixon for assistance in data collection.

\section{Authors' contributions}

PW and CMM contributed equally to the design, analysis, and writing of the manuscript. PW implemented the research and collected the data. Both authors read and approved the final manuscript.

\section{Authors' information}

Patti Waters, MA, Department of Psychology, Brock University, 500 Glenridge Avenue, St Catharines, Ontario, L2S 3A1, Canada. Cheryl M McCormick, PhD, Canada Research Chair in Behavioural Neuroscience, Professor, Centre for

Neuroscience and Department of Psychology, Brock University 500 Glenridge Avenue, St Catharines, Ontario, L2S 3A1, Canada.

\section{Competing interests}

The authors declare that they have no competing interests.

Received: 23 June 2011 Accepted: 27 September 2011

Published: 27 September 2011

\section{References}

1. Mathers C, Fat G, Boema JT: The Global Burden of Disease: 2004 Update Geneva, Switzerland: World Health Organization; 2008.

2. Bao AM, Meynen G, Swaab DF: The stress system in depression and neurodegeneration: focus on the human hypothalamus. Brain Res Rev 2008, 57:531-553.

3. Risch N, Herrell R, Lehner T, Liang KY, Eaves L, Hoh J, Griem A, Kovacs M, Ott J, Merikangas KR: Interaction between the serotonin transporter gene (5-HTTLPR), stressful life events, and risk of depression: a meta-analysis. JAMA 2009, 301:2462-2471.

4. Wang J: Work stress as a risk factor for major depressive episodes. Psychol Med 2005, 35:865-871.

5. Pariante CM, Lightman SL: The HPA axis in major depression: classical theories and new developments. Trends Neurosci 2008, 31:464-468.

6. Kessler RC, McLaughlin KA, Green JG, Gruber MJ, Sampson NA, Zaslavsky AM, Aguilar-Gaxiola S, Alhamzawi AO, Alonso J, Angermeyer M, Benjet C, Bromet E, Chatterji S, de Girolamo G, Demyttenaere K, Fayyad J, Florescu S, Gal G, Gureje O, Haro JM, Hu CY, Karam EG, Kawakami N, Lee S, Lépine JP, Ormel J, Posada-Villa J, Sagar R, Tsang A, Ustün TB, Vassilev S, Viana MC, Williams DR: Childhood adversities and adult psychopathology in the WHO World Mental Health Surveys. Br J Psychiatry 2010, 197:378-385.

7. Reardon LE, Leen-Feldner EW, Hayward C: A critical review of the empirical literature on the relation between anxiety and puberty. Clin Psychol Rev 2009, 29:1-23. 
8. Grant KE, Compas BE, Stuhlmacher AF, Thurm AE, McMahon SD, Halpert JA: Stressors and child and adolescent psychopathology: moving from markers to mechanisms of risk. Psychol Bull 2003, 129:447-466.

9. Dorn LD, Chrousos GP: The neurobiology of stress: understanding regulation of affect during female biological transitions. Sem Reprod Endocrinol 1997, 15:19-35.

10. Anisman H, Matheson K: Stress, depression, and anhedonia: caveats concerning animal models. Neurosci Biobehav Rev 2005, 29:525-546.

11. Cryan JF, Slattery DA: Animal models of mood disorders: recent developments. Curr Opin Psychiatr 2007, 20:1-7.

12. McArthur R, Borsini F: Animal models of depression in drug discovery: A historical perspective. Pharmacol Biochem Behav 2006, 84:436-452.

13. McCormick CM, Mathews IZ, Thomas C, Waters P: Investigations of HPA function and the enduring consequences of stressors in adolescence in animal models. Brain Cog 2010, 72:73-85.

14. Sterner EY, Kalynchuk LE: Behavioral and neurobiological consequences of prolonged glucocorticoid exposure in rats: relevance to depression. Prog Neuropsychopharm Biol Psychiatry 2010, 34:777-790.

15. Willner P: Chronic mild stress (CMS) revisited: consistency and behavioural-neurobiological concordance in the effects of CMS. Neuropsychobiology 2005, 52:90-110.

16. Tirelli E, Laviola G, Adriani W: Ontogenesis of behavioral sensitization and conditioned place preference induced by psychostimulants in laboratory rodents. Neurosci Biobehav Rev 2003, 27:163-178.

17. Spear LP: The adolescent brain and age-related behavioral manifestations. Neurosci Biobehav Rev 2000, 24:417-463.

18. McCormick CM, Mathews IZ: Adolescent development, hypothalamicpituitary-adrenal function, and programming of adult learning and memory. Prog Neuropsychopharm Biol Psychiatry 2010, 34:756-765.

19. Brown E: Effects of glucocorticoids on mood, memory, and the hippocampus. Treatment and preventive therapy. Ann NY Acad Sci 2009, 1179:41-55.

20. Tata DA, Anderson BJ: The effects of chronic glucocorticoid exposure on dendritic length, synapse numbers and glial volume in animal models: implications for hippocampal volume reductions in depression. Physiol Behav 2010, 99:186-193.

21. Xu Z, Zhang Y, Hou B, Gao Y, Wu Y, Zhang C: Chronic corticosterone administration from adolescence through early adulthood attenuates depression-like behaviors in mice. J Affect Disord 2011, 131:128-135.

22. McCormick CM: An animal model of social instability stress in adolescence and risk for drugs of abuse. Physiol Behav 2010, 99:194-203.

23. Morrissey MD, Mathews IZ, McCormick CM: Enduring deficits in contextual and auditory fear conditioning after adolescent, not adult, social instability stress in male rats. Neurobiol Learn Mem 2011, 95:46-56.

24. McCormick CM, Nixon F, Thomas C, Lowie B, Dyck J: Hippocampal cell proliferation and spatial memory performance after social instability stress in adolescence in female rats. Behav Brain Res 2010, 208:23-29.

25. Mathews IZ, Wilton A, Styles A, McCormick CM: Heightened neuroendocrine function in males to a heterotypic stressor and increased depressive behaviour in females after adolescent social stress in rats. Behav Brain Res 2008, 190:33-40.

26. McCormick CM, Smith C, Mathews IZ: Effects of chronic social stress in adolescence on anxiety and neuroendocrine response to mild stress in male and female rats. Behav Brain Res 2008, 187:228-238.

27. McCormick CM, Merrick A, Secen J, Helmreich DL: Social instability in adolescence alters the central and peripheral hypothalamic-pituitaryadrenal responses to a repeated homotypic stressor in male and female rats. J Neuroendocrinol 2007, 19:116-126.

28. Johnson SA, Fournier NM, Kalynchuk LE: Effect of different doses of corticosterone on depression-like behavior and HPA axis responses to a novel stressor. Behav Brain Res 2006, 168:280-288.

29. Marks W, Fournier NM, Kalynchuk LE: Repeated exposure to corticosterone increases depression-like behavior in two different versions of the forced swim test without altering nonspecific locomotor activity or muscle strength. Physiol Behav 2009, 98:67-72

30. Barr AM, Brotto LA, Phillips AG: Chronic corticosterone enhances the rewarding effect of hypothalamic self-stimulation in rats. Brain Res 2000, 875:196-201.

31. Magarinos AM, Orchinik M, McEwen BS: Morphological changes in the hippocampal CA3 region induced by non-invasive glucocorticoid administration: a paradox. Brain Res 1998, 809:314-318.
32. Pekary AE, Sattin A, Blood J, Furst S: TRH and TRH-like peptide expression in rat following episodic or continuous corticosterone.

Psychoneuroendocrinology 2008, 33:1183-1197.

33. Conrad CD, MacMillan DD, Tsekhanov S, Wright RL, Baran SE, Fuchs RA: Influence of chronic corticosterone and glucocorticoid receptor antagonism in the amygdala on fear conditioning. Neurobiol Learn Mem 2004, 81:185-199.

34. Wall PM, Messier C: Methodological and conceptual issues in the use of the elevated plus-maze as a psychological measurement instrument of animal anxiety-like behavior. Neurosci Biobehav Rev 2001, 25:275-286.

35. Castagne V, Moser P, Roux S, Porsolt RD: Rodent models of depression forced swim and tail suspension behavioral despair tests in rats and mice. Curr Protoc Neurosci 2011, 55:8.10A.11-18.10A.14.

36. Kalynchuk LE, Gregus A, Boudreau D, Perrot-Sinal TS: Corticosterone increases depression-like behavior, with some effects on predator odorinduced defensive behavior, in male and female rats. Behav Neurosci 2004, 118:1365-1377.

37. Sousa N, Madeira MD, Paula-Barbosa MM: Effects of corticosterone treatment and rehabilitation on the hippocampal formation of neonatal and adult rats. An unbiased stereological study. Brain Res 1998, 794:199-210

38. Pellow S, Chopin P, File S, Briley M: Validation of open:closed arm entries in an elevated plus maze as measure of anxiety the rat. J Neurosci Meth 1985, 14:149-167.

39. Porsolt RD, Anton G, Blavet N, Jalfre M: Behavioral despair in rats: a new model sensitive to antidepressant treatments. Eur J Pharmacol 1978, 47:379-391.

40. Perrot-Sinal TS, Gregus S, Boudreau D, Kalynchuk LE: Sex and repeated restraint interact to affect cat dor-induced defensive behavior in adult rats. Brain Res Bull 2004, 1027:161-172.

41. Cryan JF, Valentino RJ, Lucki I: Assessing substrates underlying the behavioral effects of antidepressants using the modified rat forced swimming test. Neurosci Biobehav Rev 2005, 29:547-569.

42. Overstreet DH, Griebel G: Antidepressant-like effects of CRF1 receptor antagonist SSR125543 in an animal model of depression. Eur J Pharmacol 2004, 497:49-53.

43. McCormick CM, Robarts D, Gleason E, Kelsey JE: Stress during adolescence enhances locomotor sensitization to nicotine in adulthood in female, but not male, rats. Horm Behav 2004, 46:458-466.

44. Haller J, Fuchs E, Halasz J, Makara GB: Defeat is a major stressor in males while social instability is stressful mainly in females: towards the development of a social stress model in female rats. Brain Res Bull 1999 50:33-39.

45. Stone EA, Quartermain D: Greater behavioral effects of stress in immature as compared to mature male mice. Physiol Behav 1997, 63:143-145.

46. Cameron HA, Gould E: Adult neurogenesis is regulated by adrenal steroids in the dentate gyrus. Neuroscience 1994, 61:203-209.

47. Ryabinin AE, Wang YM, Finn DA: Different levels of Fos immunoreactivity after repeated handling and injection stress in two inbred strains of mice. Pharmacol Biochem Behav 1999, 63:143-151.

48. Izumi J, Washizuka M, HayashiKuwabara Y, Yoshinaga K, Tanaka Y, Ikeda Y, Kiuchi Y, Oguchi K: Evidence for a depressive-like state induced by repeated saline injections in Fischer 344 rats. Pharmacol Biochem Behav 1997, 57:883-888.

49. Lee B, Shim I, Lee HJ, Yang Y, Hahm DH: Effects of acupuncture on chronic corticosterone-induced depression-like behavior and expression of neuropeptide $Y$ in the rats. Neurosci Lett 2009, 453:151-156.

50. Drevets WC: Prefrontal cortical-amygdalar metabolism in major depression. Ann N Y Acad Sci 1999, 877:614-637.

51. Paul SM: Anxiety and depression: a common neurobiological substrate? J Clin Psychiatry 1988, 49:13-16.

52. Richardson-Jones JW, Craige CP, Nguyen TH, Kung HF, Gardier AM, Dranovsky A, David DJ, Guiard BP, Beck SG, Hen R, Leonardo ED: Serotonin$1 \mathrm{~A}$ autoreceptors are necessary and sufficient for the normal formation of circuits underlying innate anxiety. J Neurosci 2011, 31:6008-6018.

53. Parks $C L$, Robinson PS, Sibille $E$, Shenk $T$, Toth M: Increased anxiety of mice lacking the serotonin(1A) receptor. Proc Natl Acad Sci USA 1998, 95:10734-10739.

54. Karten YJG, Nair SM, van Essen L, Sibug R, Joels M: Long-term exposure to high corticosterone levels attenuates serotonin responses in rat hippocampal CA1 neurons. Proc Natl Acad Sci USA 1999, 96:13456-13461. 
55. Karanges E, Li KM, Motbey C, Callaghan PD, Katsifis A, McGregor IS: Differential behavioural and neurochemical outcomes from chronic paroxetine treatment in adolescent and adult rats: a model of adverse antidepressant effects in human adolescents? Int J Neuropsychopharmacol 2011, 14:491-504.

56. Pung T, Zimmerman $\mathrm{K}$, Klein B, Ehrich M: Corticosterone in drinking water: altered kinetics of a single oral dose of corticosterone and concentrations of plasma sodium, albumin, globulin, and total protein. Tox Indust Health 2003, 19:171-182.

57. Conrad CD, McLaughlin KJ, Harman JS, Foltz C, Wieczorek L, Lightner E, Wright RL: Chronic glucocorticoids increase hippocampal vulnerability to neurotoxicity under conditions that produce CA3 dendritic retraction but fail to impair spatial recognition memory. J Neurosci 2007, 27:8278-8285.

58. Nacher J, Pham K, Gil-Fernandez V, McEwen BS: Chronic restraint stress and chronic corticosterone treatment modulate differentially the expression of molecules related to structural plasticity in the adult rat piriform cortex. Neuroscience 2004, 126:503-509.

59. Lussier AL, Caruncho HJ, Kalynchuk LE: Repeated exposure to corticosterone, but not restraint, decreases the number of reelin-positive cells in the adult rat hippocampus. Neurosci Lett 2009, 460:170-174

60. Woolley C, Gould E, McEwen BS: Exposure to excess glucocorticoids alters dendritic morphology of adult hippocampal pyramidal neurons. Brain Res 1990, 531:225-231.

61. Watanabe Y, Gould E, Cameron HA, Daniels DC, McEwen BS: Phenytoin prevents stress-induced and corticosterone-induced atrophy of CA3 pyramidal neurons. Hippocampus 1992, 2:431-435.

62. Stone EA, Lin Y: An anti-immobility effect of exogenous corticosterone in mice. Eur J Pharmacol 2008, 580:135-142.

63. Gourley SL, Kiraly DD, Howell JL, Olausson P, Taylor JR: Acute hippocampal brain-derived neurotrophic factor restores motivational and forced swim performance after corticosterone. Biol Psychiatry 2008, 64:884-890.

64. David DJ, Samuels BA, Rainer Q, Wang JW, Marsteller D, Mendez I, Drew M, Craig DA, Guiard BP, Guilloux JP, Artymyshyn RP, Gardier AM, Gerald C, Antonijevic IA, Leonardo ED, Hen R: Neurogenesis-dependent and -independent effects of fluoxetine in an animal model of anxiety/ depression. Neuron 2009, 62:479-493.

65. Enkel T, Koch M: Chronic corticosterone treatment impairs trace conditioning in rats with a neonatal medial prefrontal cortex lesion. Behav Brain Res 2009, 203:173-179.

66. Ellis FW: Effect of ethanol on plasma corticosterone levels. J Pharmacol Exper Therapeut 1966, 153:121-127.

67. Buck HM, Hueston CM, Bishop C, Deak T: Enhancement of the hypothalamic-pituitary-adrenal axis but not cytokine responses to stress challenges imposed during withdrawal from acute alcohol exposure in Sprague-Dawley rats. Psychopharmacology .

68. Rasmussen DD, Boldt BM, Bryant CA, Mitton DR, Larsen SA, Wilkinson CW: Chronic daily ethanol and withdrawal: 1. Long-term changes in the hypothalamo-pituitary-adrenal axis. Alcohol Clin Exp Res 2000, 24:1836-1849.

69. Ogilvie KM, Rivier C: Gender difference in hypothalamic-pituitary-adrenal axis response to alcohol in the rat: activational role of gonadal steroids. Brain Res 1997, 766:19-28.

70. Silveri MM, Spear LP: Characterizing the ontogeny of ethanol-associated increases in corticosterone. Alcohol 2004, 32:145-155.

71. Allen CD, Lee SY, Koob GF, Rivier CL: Immediate and prolonged effects of alcohol exposure on the activity of the hypothalamic-pituitary-adrenal axis in adult and adolescent rats. Brain Behav Immun 2011, 25:550-560.

72. Spear LP, Varlinskaya El: Sensitivity to ethanol and other hedonic stimuli in an animal model of adolescence: implications for prevention science? Dev Psychobiol 2010, 52:236-243.

73. Allen $C D$, Rivier CL, Lee SY: Adolescent alcohol exposure alters the central brain circuits known to regulate the stress response. Neuroscience 2011, 182:162-168.

74. Przybycien-Szymanska MM, Rao YS, Pak TR: Binge-pattern alcohol exposure during puberty induces sexually dimorphic changes in genes regulating the HPA axis. Am J Physiol Endocrinol Metab 2009, 298:E320-328.

75. Cantwell DP, Baker L: Manifestations of depressive affect in adolescence. J Youth Adolesc 1991, 20:121-133.
76. Rockhill C, Kodish I, DiBattisto C, Macias M, Varley C, Ryan S: Anxiety disorders in children and adolescents. Curr Probl Pediatr Adolesc Health Care 2010, 40:66-99.

77. Beesdo K, Knappe S, Pine DS: Anxiety and anxiety disorders in children and adolescents: developmental issues and implications for DSM-V. Psychiatr Clin North Am 2009, 32:483-524.

78. Doremus TL, Varlinskaya El, Spear LP: Age-related differences in elevated plus maze behavior between adolescent and adult rats. Ann N Y Acad Sci 2004, 1021:427-430.

79. Genn RF, Tucci SA, Thomas A, Edwards JE, File SE: Age-associated sex differences in response to food deprivation in two animal tests of anxiety. Neurosci Biobehav Rev 2003, 27:155-161.

doi:10.1186/2045-5380-1-4

Cite this article as: Waters and McCormick: Caveats of chronic exogenous corticosterone treatments in adolescent rats and effects on anxiety-like and depressive behavior and hypothalamic-pituitary-adrenal (HPA) axis function. Biology of Mood \& Anxiety Disorders 2011 1:4.

\section{Submit your next manuscript to BioMed Central and take full advantage of:}

- Convenient online submission

- Thorough peer review

- No space constraints or color figure charges

- Immediate publication on acceptance

- Inclusion in PubMed, CAS, Scopus and Google Scholar

- Research which is freely available for redistribution

Submit your manuscript at www.biomedcentral.com/submit
C) Biomed Central 